\title{
Nonmucinous Cystic Neoplasm of the Pancreas with Ovarian-like Stroma
}

\author{
Kei Yane ${ }^{1, \odot ~ H i d e y u k i ~ I h a r a ~}{ }^{1}$ Tetsuya Sumiyoshi ${ }^{1}$ \\ 1Department of Gastroenterology, Tonan Hospital, Sapporo, \\ Hokkaido, Japan \\ 2Department of Pathology, Tonan Hospital, Sapporo, Hokkaido, \\ Japan
}

J Digest Endosc 2021;12:118-119.

A 50-year-old woman was admitted to our hospital for close examination of an enlarging pancreatic cyst. CT and MRI showed a $55-\mathrm{mm}$ cyst with a thin wall in the tail of the pancreas without an apparent mural nodule. The pancreatic parenchyma was normal and there was no dilatation of the main pancreatic duct. Endoscopic ultrasonography showed a $45-\mathrm{mm}$ cyst with a thin wall and no septations. The cyst had two $5-\mathrm{mm}$ mural cysts (-Fig. 1). There was no apparent blood flow in the mural cysts on color Doppler imaging. The main pancreatic duct was $2 \mathrm{~mm}$ in diameter without dilatation, and the rest of the pancreatic parenchyma had no abnormality. There was no apparent communication between the pancreatic duct and the cyst. The cyst was initially diagnosed as mucinous cystic neoplasm, based on age, sex, location, and imaging findings. For a definitive diagnosis and treatment, the patient underwent laparoscopic distal pancreatectomy. Grossly, the cyst had a thin uniform wall, a smooth inner surface, and small mural cysts $(6 \mathrm{~mm})$ (-Fig. 2). The cyst contents were serous. Pathological findings showed that the cyst epithelium was lined with a single layer of nondysplastic cuboidal cells with no mucus. Beneath the epithelium was a layer composed of spindle cells resembling ovarian stroma.

DOI https://doi.org/ 10.1055/s-0041-1731976 ISSN 0976-5042

\author{
Hitoshi Kondo $^{1}$ Yumiko Oyamada ${ }^{2}$
}

For the immunohistochemistry finding, the ovarian-like stroma was positive for progesterone receptor ( $\mathbf{F i g . ~} \mathbf{3}$ ). The final diagnosis was nonmucinous cystic neoplasm of the pancreas with ovarian-like stroma. This is a rare case of benign pancreatic cystic neoplasm, mimicking the imaging findings of mucinous cystic neoplasm.

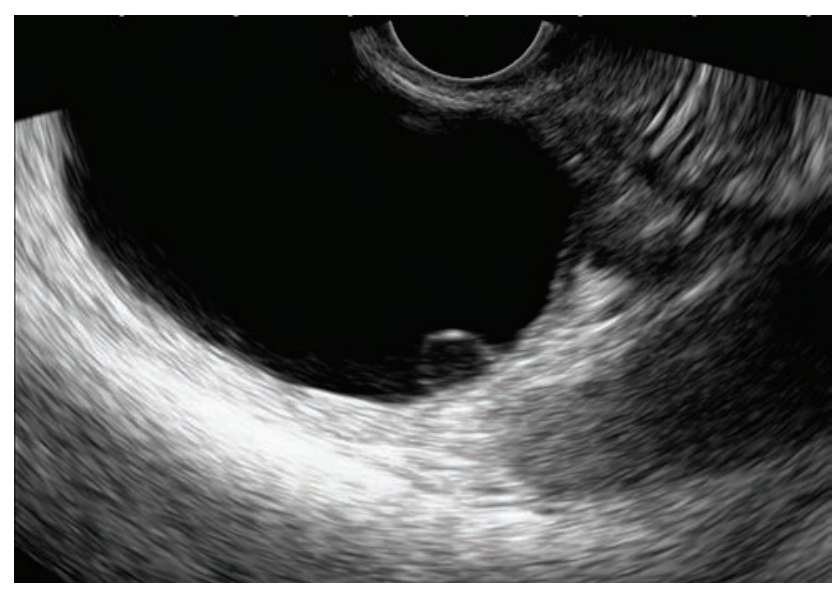

Fig. 1 Endoscopic ultrasonography showed a 45-mm cyst with a thin wall with no septations. The cyst had two 5-mm mural cysts. (c) 2021. Society of Gastrointestinal Endoscopy of India.

This is an open access article published by Thieme under the terms of the Creative Commons Attribution-NonDerivative-NonCommercial-License, permitting copying and reproduction so long as the original work is given appropriate credit. Contents may not be used for commercial purposes, or adapted, remixed, transformed or built upon. (https://creativecommons.org/licenses/by-nc-nd/4.0/).

Thieme Medical and Scientific Publishers Pvt. Ltd. A-12, 2nd Floor, Sector 2, Noida-201301 UP, India 

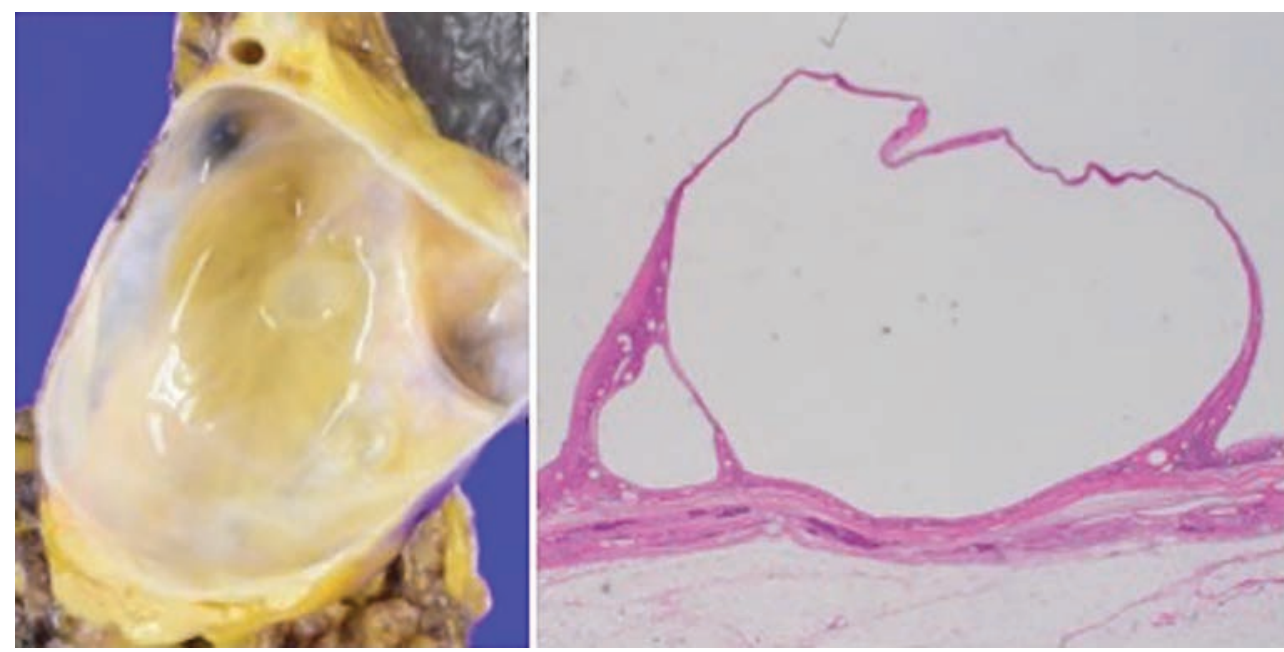

Fig. 2 Grossly, the cyst had a thin uniform wall, a smooth inner surface, and small mural cysts.

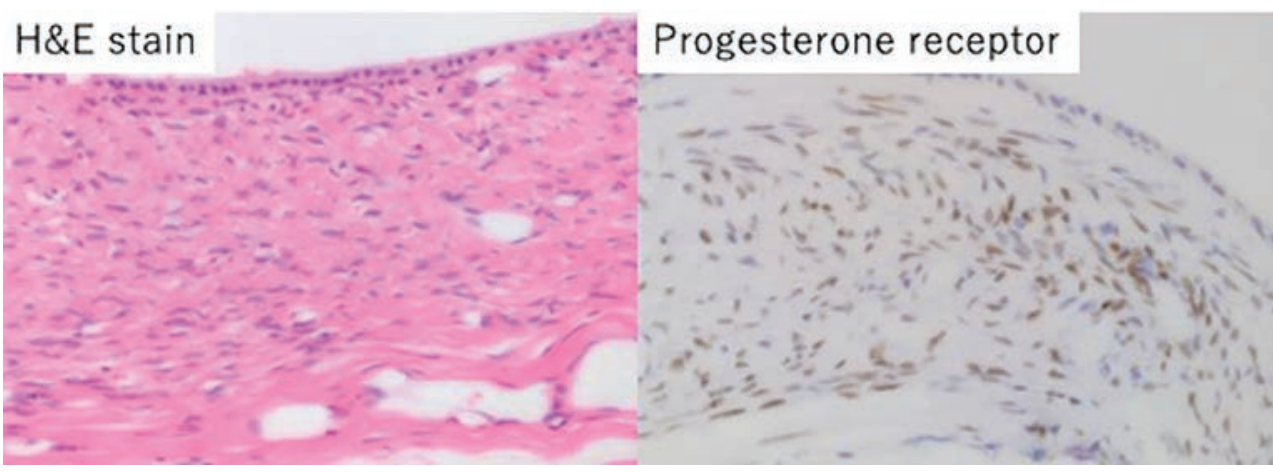

Fig. 3 Pathological findings showed that the cyst epithelium was lined with a single layer of nondysplastic cuboidal cells with no mucus. Beneath the epithelium was a layer composed of spindle cells resembling ovarian stroma. For the immunohistochemistry finding, the ovarian-like stroma was positive for progesterone receptor.

\section{Author Contributions}

A. Yane wrote the paper; H. Ihara performed patient care; T. Sumiyoshi and H. Kondo supervised the paper writing, made important revisions, and approved the final manuscript; Y. Oyamada performed pathological diagnosis.

\section{Conflict of Interest}

None declared. 